\title{
Happiness as Correlates of Mental Well-Being
}

\author{
Shama Rahman ${ }^{1}$, Shamim A. Ansari ${ }^{2}$, Farzana Parveen ${ }^{3}$
}

\section{ABSTRACT}

The quality of a nation depends upon the good mental health of adolescent students. Though the purpose of my study to explore whether happiness is associated with mental well-being among adolescents. The concept of mental health contains aspect of our emotional, psychological and social well-being and not merely the absence of disease. Happiness is the positive key factor of human daily life and was introduced as a main component of health by the WHO. Happiness is based on a life-long pursuit of meaningful, developmental goals. The purpose of this study was to explore the relationship between happiness and mental well-being among adolescent students. For this purpose a sample consisting $\mathrm{N}=100$ adolescent students (male=50 and female=50). Sample was taken from Aligarh Muslim University, Aligarh. Mental well-being scale by Tenant et al. (2007) used to check the mental well-being among adolescents. And Oxford Happiness Questionnaire by psychologist Michael Argyle and Peter Hills (1989) to check the happiness level of adolescent students. Result was analyzed by SPSS software. Positive correlation ( $\mathrm{r}=.670)$ was found between happiness and mental well-being among adolescent students. Insignificant difference had found between male and female adolescence on happiness level $(\mathrm{t}=1.207)$ \& mental well-being level ( $\mathrm{t}=.105)$. Thus, happiness can enhance the mental well-being of a person, which is beneficial for a person's healthy life style.

Keywords: Mental health, happiness and adolescent students.

In present decade adolescents mental problem are increasing day by day. This problem is very sever and dangerous for society as well as our nation. Happiness is positive key factor that contribute important role in promoting mental well-being of a person. In words of two American Social psychologists:

The investigation and application of positive human development is new perspective that was need now more and ever (Moore \& Keyes, 2003).

\footnotetext{
${ }^{1}$ Research Scholar Department of Psychology, Aligarh Muslim University, Aligarh

${ }^{2}$ Professor Department of Psychology, Aligarh Muslim University, Aligarh

${ }^{3}$ Research Scholar Department of Psychology, Aligarh Muslim University, Aligarh

*Responding Author

(C) 2016 I S Rahman, S Ansari, F Perveen; licensee IJIP. This is an Open Access Research distributed under the terms of the Creative Commons Attribution License (http://creativecommons.org/licenses/by/2.0), which permits unrestricted use, distribution, and reproduction in any Medium, provided the original work is properly cited.
} 


\section{Happiness as Correlates of Mental Well-Being}

WHO has included mental well-being in the definition of Health. WHO defines mental health as "a state of complete physical, mental and social well-being and not merely the absence of disease or infirmity (WHO, 2001). According to WHO, mental health defined as a state of well-being in which people realize their own potential, can cope with normal life stresses, can work productively and can contribute to their community (WHO 2001b). Mental health studies show that 450 million people worldwide have a mental or behavioral disorder. Besides these out of every four people experiences a mental or behavioral problem at least once in a life time (WHO). Reese (2001) refers to wellness as "a self-awareness process of health and altering behavior, aiming towards a healthier physical, mental, emotional, psychological, occupational and spiritual state”. Thus mental wellness can be considered as absence of mental illness and positive evaluation of life.

Mental well-being includes the capacity to make health and happiness enhancing relationship with others. A person with mentally well know themselves and their needs, have clear goals, can relate to others using the skill of emotional literacy and can accept and manage conflicts very well without manipulation. People with mental well-being experience peace of mind, contentment, happiness and joy. Mentally well people can cope with life's ups and downs and be confident and resilient. Thus, mental well-being is more than absence of mental illness/disorders. It represents the positive side of mental health and could achieve by people with a diagnosis of mental disorder.

Studies showing that having mental healthy person can deal with difficult situation in a better manner (Smith \& Segal, 2011) and they remain focused, flexible \& creative at all times.

Happiness is most important key factor of human daily life and had introduced as main component of health by World Health Organization (Cohn et al.,2009). According to Aristotle, the realization of one's potential was a critical integrant of happiness, or eudemonia (Waterman, 1990). Similarly, according to some other theorists, happiness emerges when several specific life conditions have met, such as self-acceptance, environmental mastery, personal growth and relatedness (Ryan \& Deci, 2001; Ryff, 1989). The meaning of happiness use to denote the preponderance of positive effects such as joy, interest, and pride over the negative effects such as sadness, anxiety and anger (Lyubomirsky, King \& Diener).Study has found that measures of well-being, defined by aspect of healthy functioning, show negative correlation with symptoms of mental illness (Keyes, 2003).

Happiness considered as one of the important determinants of the subjective well-being (Honkanen et al.,2005). Happy people have more self-esteem, sense of control optimism and sense of purpose derived from having goals. All factors positively related to mental well-being of a person. Skevington, MacArthur, and Somerset (1997) found with a no of focus groups in England that happiness had rated as the most important component of Quality of life, greater 


\section{Happiness as Correlates of Mental Well-Being}

than money, health or sex. Studies shows that happy people report low level of mental illness symptoms (Diener \& Seligman, 2002).

Happiness play very important role in a well-being of a person. Study revealed that happiness could lead to well-being of individual and communities and never has negative consequences on humans and humanities (O’ Brien, 2008). Another research finding showed that people who are happier achieve better life outcomes i.e. higher coping skill, supportive relationship, good financial performance and physical health as well as longevity (Piqueras et al.2011).

The objectives of present study are-

- $\quad$ To find out relationship between happiness and mental well-being among adolescence.

- $\quad$ To explore the difference on happiness among male female adolescence.

- $\quad$ To explore the difference on mental well-being among male female adolescence.

On the basis of the literature, the hypotheses of present study are-

- $\quad$ There will be positive relationship between happiness and mental well-being among adolescents.

- $\quad$ There will be no significance difference of happiness between male and female adolescence.

- $\quad$ There will be no significance difference of mental well-being between male and female adolescence.

\section{METHODS}

\section{Participants-}

The sample for the present study comprised of $(\mathrm{N}=100)$ male and female adolescence students of Aligarh Muslim University of 10th standard. Out of 100 students, there are 50 male and 50 female students. Their age ranged from 14-16 years.

\section{Tools-}

1. Oxford Happiness Questionnaire (Argyle and Hills, 2002). It is 6 point rating scale with response categories ranging from strongly disagree with a score of 1 to strongly agree with a score of 6 . It has 29 items with test re-test reliability of 0.91 . The inter item correlation ranged from 0.04 to 0.65 and mean score found 0.28 .

2. The Warwick-Edinburgh Mental well-being scale (WEMWBS) developed by Tennant et al. (2007). It was founded by Scottish Government National programmed for improving Mental Health and Well-Being, this measure was used to assess the mental health of adolescents. It is a 5-point likert scale that is consisting of 14 items. Cronbach's alpha coefficient is 0.84 and test retest reliability of the scale is 0.83 .

\section{Procedure-}

After establishing the rapport, some appropriate instruction had given to the participants. Data had collected individually from each participant. As soon as the subject completed both questionnaires, questionnaire had collected. After collecting the data scoring was done manually. 


\section{Happiness as Correlates of Mental Well-Being}

\section{Statistical Analysis-}

Statistical analysis was done in accordance of the objective of the study. Pearson product moment correlation has used to find the relationship between happiness and mental well-being among adolescence students. And t-test was used to find out difference between male and female adolescence students. Data were analyzed by SPSS version 20.0.

\section{RESULT AND DISCUSSION}

Table1. Shows the correlation between happiness and mental well-being among over all adolescence.

\begin{tabular}{|l|l|l|l|l|}
\hline Variables & Mean & SD & N & R \\
\hline Happiness & 4.24 & .67 & \multirow{2}{*}{100} & .670 \\
\cline { 1 - 3 } Mental well-being & 53.59 & 8.52 & & \\
\hline
\end{tabular}

Correlation is significant at 0.01 levels (two tailed).

Table no 1. Shows the score of happiness $(\mathrm{N}=100$, Mean=4.24, $\mathrm{SD}=53.59)$ and mental wellbeing $(\mathrm{N}=100$, mean=53.59, $\mathrm{SD}=8.52)$ among adolescents respectively. The correlation value of happiness and mental well-being had found.670 that shows significant correlation at 0.01 levels.

Table2. Shows correlation between happiness and mental well-being among male and female adolescence.

\begin{tabular}{|l|l|l|l|l|l|}
\hline Gender & Variables & Mean & SD & N & R \\
\hline \multirow{2}{*}{ Male } & Happiness & 4.15 & .66 & \multirow{2}{*}{50} & .637 \\
\cline { 2 - 4 } Female & $\begin{array}{l}\text { Mental well- } \\
\text { being }\end{array}$ & 53.68 & 9.03 & \multirow{2}{*}{50} & \multirow{2}{*}{.723} \\
\cline { 2 - 4 } & $\begin{array}{l}\text { Happiness } \\
\text { Mental well- }\end{array}$ & 4.31 & .67 & \\
\hline
\end{tabular}

Correlation is significant at the 0.01 level (two tailed).

Table no 2. Shows the correlation value of male and female adolescents separately. Male score of happiness ( $\mathrm{N}=50$. Mean=4.15, $\mathrm{SD}=.66)$ and mental well-being $(\mathrm{N}=50$, Mean=53.68, $\mathrm{SD}=9.03)$ and their correlation value were found .637, that shows significant correlation at 0.01 level. Female score of happiness $(\mathrm{N}=50, \mathrm{Mean}=4.31, \mathrm{SD}=.67)$ and mental well-being $(\mathrm{N}=50$, Mean=53.50, SD=8.08) and their correlation value were found $\mathbf{. 7 2 3}$, that also shows significant correlation at the 0.01 level. 
Table3. Showing the mean difference of happiness and mental well-being among male female adolescents.

\begin{tabular}{|l|l|l|l|l|l|l|}
\hline Variables & Gender & $\mathbf{N}$ & Mean & SD & df & t value \\
\hline \multirow{2}{*}{ Happiness } & Male & 50 & 4.15 & .66 & 98 & \multirow{2}{*}{1.207} \\
\cline { 2 - 6 } & Female & 50 & 4.31 & .67 & & \\
\hline \multirow{2}{*}{ Mental well-being } & Male & 50 & 53.68 & 9.03 & \multirow{2}{*}{.08} & \multirow{2}{*}{.105} \\
\cline { 2 - 5 } & Female & 50 & 53.50 & 8.04 & & \\
\hline
\end{tabular}

Table no 3. Shows the mean difference of happiness and mental well-being among male and female adolescence. The mean difference of happiness among male adolescents ( $\mathrm{N}=50$, Mean=4.15, $\mathrm{SD}=.66)$ and female adolescents $(\mathrm{N}=50$, Mean $=4.31, \mathrm{SD}=.67)$ were found $(\mathrm{t}=1.207$, $\mathrm{p}>0.05$ ), which is insignificant at 0.05 level. The mean difference of mental well-being among male $(\mathrm{N}=50$, Mean=53.68, $\mathrm{SD}=9.03)$ and female $(\mathrm{N}=50$, Mean=53.50, $\mathrm{SD}=8.04)$ were found $(\mathrm{t}=.105, \mathrm{p}>0.05)$, which is also insignificant at 0.05 level. Thus our null hypotheses $\left(\mathrm{H}_{0}\right)$ were accepted. There is no significance difference between male and female on happiness and mental well-being dimensions of adolescent students.

Above result shows that there are a positive correlation between happiness and mental wellbeing among male and female adolescents. Thus our alternate hypotheses $\mathrm{H}_{1}$ is accepted, there are positive correlation exist between male and female adolescents. It means that happiness is the best promoter of better mental well-being of adolescents. Study conducted by Diener and Seligman (2002) found that happiest group of people had few symptoms of psychopathology, such as depression, hypochondrias is or schizophrenia. Another study conducted by Kambiz Kamkay et al. (2012) supported our finding. They conducted their study on Tehran youth people and found the significant correlation between happiness and mental health among Tehran youth people. Thus, we can simply say that positivism or happiness is the significant predictor of mental and psychological well-being of a person. Findings also suggests that if a person are mentally healthy, they can enjoy their life more happily way.

Perneger et al. (2004), conducted a cross sectional study on young Swiss adults and found strong association between happiness and mental health. Thus if people are happy may help to identify mental health care needs. They can able to do good care of themselves as well as society. Happiness may also be a useful outcome measure for evaluation of health intervention. Nazirul Hasnain et al. (2014), conducted a study on Assamese male and female, they concluded that hope and happiness emerged as significant predictor of psychological well-being youth adults. Another research evidences indicate that there are significant correlation between happiness and general health outcomes such as commitment to have higher level of physical exercise, having a 


\section{Happiness as Correlates of Mental Well-Being}

healthy sleeping pattern, healthy diet and commitment to keep away from smoking or drinking alcohol (Blood Worrth and McNamee, 2007).

This study also shows that there is no significance difference between male and female on mental well-being and happiness dimensions. It means that male and female adolescents do not differ from each other. Both had found equal score on both the happiness and mental well-being level. Present study supported by the study conducted by Srividhya and Khadi (2007). They conducted their study among adolescents and found that boys and girls did not differ in mental health status and there is no influence of age, type of family, ordinal position, sibling status and family income on mental health of students. Happiness becomes major goal in life around the world (Diener \& Oishi, 2006).

\section{CONCLUSION}

We can conclude that happiness is the important key factor for promoting and enhancing mental well-being of an individual. When a person is mentally healthy can deal with difficult situation in a better manner (Smith and Segal, 2011). As researches indicate that mental health, problems are the biggest contribution to poor well-being (Layard et al. 2013). So happiness can enhances the mental well-being among adolescence and the can enjoy the fully functioning life. Boys and girls both are same at happiness and mental well-being dimension, happiness can enhances their mental well-being equally. Thus, we can develop many intervention program of happiness to enhance the mental well-being of adolescents.

\section{REFERENCES}

Bloodworth and McNamee, (2007) Cohn, M.,Fredrickson, B., Brown, S.,Mikels, J., Conway, A.,(2009). Happiness unpacked: positive emotions increase life satisfaction by building resilience. Emotion 9 (3), 361-368.

Diener, E., \& Oishi, S. (2006). The desirability of happiness across cultures. Unpublished manuscript, University of Illinois, Urbana-Champaign.

Diener, E., \&Seligman, M. E. P. (2002). Very happy people. Psychological Science,13, 81-84.

Hasnain N., Wazid, S.W. and Hasan, Z. (2014). Optimism, Hope, and Happiness as correlates of Psychological Well-Being between young adult Assamese male and female. IOSR Journal Of Humanities And Social Science (IOSR-JHSS), Volume 19, Issue 2, Ver. II, PP 44-51. e- ISSN: 2279-0837, p-ISSN: 2279-0845.

Heizomi, H., Allahverdipour, H., Asghari Jafarabadi, M. et al.,2015. Happiness and its relation to psychological well-being of adolescents. Asian journal of psychiatry, 16, 55-60.

Hills, P., \& Argyle, M. (2002). The Oxford Happiness Questionnaire: a compact scale for the measurement of psychological well-being. Personality \& Individual Differences, 33, 1073-1082.

Honkanen, H., Jaakko Kaprio, J., Honkanen, R., Viinamaki, H., Koskenvuo, M., 2005. The stability of life satisfaction in a 15-years follow-up of adult Finns healthy at baseline. BioMed Cent. Psychiatry 5 (4). 


\section{Happiness as Correlates of Mental Well-Being}

http://www.fph.org.uk/concepts_of_mental_and_social_wellbeing

Kamkary, K. and Shokrzadeh, S. (2012). Investigate relationship between mental health and happiness feels in Tehran youth people. European Journal of Experimental Biology, 2, (5): 1880-1886.

Layard, R., Chesholm, Patel, V. et al. (2013). Mental illness and unhappinessCentre for economic performance, LSE, September.

Michael Argyle. The psychology of happiness, $2^{\text {nd }}$ edition, special Indian edition.

Moore, K.A. and Keyes C.L.M.(2003) 'Introduction', pp. 1-11 in Bornstein.

O’Brien, C., (2008). Sustainable happiness: how happiness studies can contribute to a more sustainable future. Can. Psychol. 49 (4), 289-295.

Perneger, T. V., Hudelson, P. M. and Bovier, P. A. (2004). Health and Happiness in young Swiss adults. Qual Life Res, Feb; 13 (1): 171-178.

Piqueras, J., Kuhne, W., Villarroel, P., Straten, A., Cuijper, P., 2011. Happiness and health behaviors in Chilean college students: a cross-sectional survey. BMC Public Health 11 (443).

Ryan, R. M.,\& Deci, E. L. (2001). On happiness and human potentials: A review of research on hedonic and eudemonic well-being. Annual Review of Psychology, 52, 470-489.

Ryff, C.D. (1989). Happiness is everything, or is it? Explorations on the meaning of psychological well-being. Journal of Personality and Social Psychology, 57, 1069-1081.

Skevington, S.M.,MacArthur, P., \& Somerset, M.(1997). Developing items for the health in Britain. British journal of health psychology, 2, 55-72.

Srividhya \& Khadi, P. B. (2007). Mental health and adjustment problem of students of Navodhaya, Central and State Schools. Retrieved from Etd. Uasd. Edu/Ft/Th9578. Pdf on 21/09/2012.

Tennant R,Hiller L,Fishwick R, Platt S, Joseph S, Weich S, Parkinson J, Secker S, and StewartBrown S (2007). The Warwick-Edinburgh Mental well-being Scale (WEMWBS): development and UK validation. Health and Quality Of Life Outcomes, 5 (63), doi: 10.1186/1477-7525-5-63.

Waterman, A.S. (1990). The relevance of Aristotle's conception of eudemonia for the psychological study of happiness. Theory and Philosophy of Psychology, 10, 39-44.

WHO (2001a). Basic documents, $43^{\text {rd }}$ edn. Geneva World Health Organization.

WHO (2001b). Strengthening mental health promotion. Geneva, World health organization (fact sheet no.220).

World Health Organization (WHO) (2001). The World Health Report: Mental Health, New understanding, New hope. World Health Organization, Geneva.

How to cite this article: S Rahman, S Ansari, F Perveen (2016), Happiness as Correlates of Mental Well-Being, International Journal of Indian Psychology, Volume 3, Issue 3, No. 5, DIP: 18.01.094/20160303 